\title{
"I am going abroad to study English": language learning beyond words and grammar
}

\section{Annarita Magliacane}

Department of French, UCC

Learning another language is not only learning different words for the same thing, but learning another way to think about things (Flora Lewis, Dialogue among Civilizations, United Nations, New York, 5 September 2000)

\section{Introduction}

Studying abroad, and particularly in an English-speaking environment, has become very popular among English learners in the last few decades. Every year, thousands of students leave their own countries to start or to continue their university studies in an Englishspeaking context. One of the reasons behind this trend is that living in the target language community, i.e. the country where the language learnt at school is officially spoken, provides them with more opportunities to learn a language than in their homeland. In fact, there seems to be a general consensus among teachers, students and parents that a period of time spent in the target language community by the 'instructed learner', i.e. the student who has mainly studied the language in a classroom setting outside the target language community, is beneficial to the acquisition of a foreign language.

\section{Seeing the "new" world through the eyes of a child}

Students, upon their arrival in the target language community, often mention that in a study abroad context they can learn English faster and better than they can do in their home countries. They often report having more opportunities to practise the language, to speak English in and outside the classroom with their friends, instructors, housemates, local people that they meet, for instance, while waiting for the bus or queuing at the supermarket. In the first few weeks they have the impression of learning a lot, especially in terms of lexicon in relation to their daily life. For example, they start learning to name the kitchenware or the different ways of referring to cleaning products, which are not simply 'the soap for', as they might say when trying to recall the most appropriate word or try to explain what they are referring to.

This gives them a sense of excitement as they expand their vocabulary very quickly and this way of learning seems very different from the teaching style in their home countries 
where all these words are generally not taught. The speaking practice is often limited to a few 'discuss with your partner' oral exercises where students are supposed to orally reproduce with a classmate what is written in a dialogue, using more or less the same linguistic structures, i.e. the manner in which words, grammar, syntax, and the meaning of words are organised and used. They also often complain that in their home countries they learn to speak about very serious issues, such as pollution or globalisation, but they often do not know the names of 'that thing for a headache' or 'that thing to use when the battery of your phone is dying', which are useful things in their everyday lives.

Thus, because of this sense of general improvement in the foreign language, study abroad is so common, popular, and for some students, even trendy. In fact, today the so-called 'experience abroad' is no longer exceptional but is often part of a university path and is considered by many to have a fundamental role in the lives of young people. Therefore, most students, especially at third level, spend part of their studies in another country for a short while, commonly availing of grants or little subsistence, provided by the European Union or similar organisations. These funds, together with the current European policies, seem to favour students' international mobility and enhance the idea of the desirability of the experience abroad as they contribute to foster the popular belief, giving it even a sort of scientific aura.

\section{The grass is not always greener on the other side}

However, this honeymoon phase of living abroad is not supposed to last until the end of the experience. Little by little, the students realise that they had more expectations about their language learning abroad in particular with regard to their relationships with the local people. Despite the fact that they might practise the language more frequently in comparison to their home countries, where the chances of using the language might be limited to the classroom setting, their expectations regarding their social participation in the target language community and, in particular, their interaction with the local people, might not be totally fulfilled. In fact, it seems that they expected to have more Irish friends and further chances of practising the language with native speakers. After a few weeks they realise that it is easier to "hang out" with other international students. They share the same experience, they go to the same events which become a sort of "chain reaction" with regard to students' social networks. For example, one of the students who took part in the project said

"Your French friend will introduce you to more French people, who will introduce you to other students, who are often French or international students".

Interaction with native speakers is often limited to superficial conversations, such as housekeeping or asking university staff, other students or local people for general information. In these conversations with native speakers, the students feel that the language 
is still a problem, sometimes even a barrier, for them. The accent is very hard and sometimes they do not manage to understand even words or structures that they know or they should know. One of the students interviewed, for instance, mentioned, during one of the meetings, how she found out that some sounds in Irish English are pronounced slightly different from the so-called standard pronunciation that she was taught in the classroom. At the very beginning of her experience, even a simple question 'Are you going to take the bus?' was the cause of a puzzled expression on her face. She understood most of the words; she recognised the grammatical structure (her teacher in Italy called it intentional future'), but she could not figure out what her interlocutor meant with the last word which sounded to her ears something like 'boss'.

However, while one may think that the accent is one of the main issues that might cause misunderstandings, there is much more beneath the surface. Although all of the students interviewed mentioned that the accent in Cork is quite difficult for them, when asked what the oddest thing was to them about Irish people, only a very small percentage mentioned the accent or their way of pronouncing some particular words, like 'bus', 'pub' or 'Dublin'. The majority of the students interviewed found it very awkward that such a welcoming and nice community

"if they see you in the street with a map, they will ask you if you need help" (said one of the interviewees)

have the strange habit of asking about the general health of their interlocutor ("Hi, how are ya?"), but they do not seem very concerned about their response. Actually, before the students could even utter a sound, Irish people are miles away, no matter what the response is.

\section{Beyond linguistic competence}

Why does this happen? What is the cause of this break in communication? When nonnative speakers of English start learning the language they probably came across dialogues like the one below:

Margaret: Hi Ann. How are you?

Ann: I am fine, thanks. And you?

Margaret: I feel bad. I think I am sick.

Ann: I hope you feel better soon

Therefore, when they meet a person or they are asked 'How are ya?', they would like to reproduce the same type of conversation or, at least, this is what they expect to happen, but, strangely, the interlocutor does not wait for their response.

Whereas for Irish people 'Hi, how are ya?' is simply a way of saying 'hello', students probably find it awkward as they do not understand exactly the pragmatic intention of the utterance, as linguists would say. What do linguists mean by 'pragmatic intention'? 
Pragmatics is a branch of linguistics which studies how the language is actually used rather than how it should be used. The word 'pragmatic' is also used in everyday language to describe a person who likes to solve problems in a practical and sensible way, rather than relying on fixed rules or dogmas, and that is basically what this branch of linguistics does. Instead of relying on the knowledge "by the book", pragmatics tries to find out the deeper meaning, considering other factors, like context, background knowledge of the speaker and the listener, and also the place where the language is spoken.

English, in fact, is not always the same everywhere and rather than speaking of English, we should speak of Englishes. Students in their classroom are probably exposed to one of the most important varieties of English, the so-called Standard English, which is the most prestigious one but, at the same time, the least frequently spoken. Thus, the fact that the students might find it strange that Irish people do not respond to 'how are you?' might be related to other factors, which are beyond the morphological level, i.e. the words that are actually written or pronounced. Moreover, when Irish people do respond to 'How are you?', they rarely use 'Fine, thanks' but they might use other equivalent expressions, which might sound a bit weird to a non-native English speaker's ears. For instance, they might say 'Not too bad!', even though there is nothing wrong with them, or 'I'm grand!', which might sound as if they had won the lottery or they are overexcited.

Thus, language varies, from country to country, where it is officially spoken, from region to region and, even within the same community. This is an important factor to consider while analysing the language development of students who live in the target language community and will be exposed to that language, or, as some linguists would name it, variety. This language input may have some effects on their language development; they may pick up some of the features of the variety consciously, for a sense of group inclusion or simply imitation, or unconsciously, i.e. they only reproduce what they hear. Otherwise, they might simply become well aware of the fact that English varies and it is not just what is in the book.

\section{The aim of my research}

By focusing on the fascinating field of pragmatics and language variation, the aim of my research project is to analyse how students' language skills develop over a period of time spent abroad. In particular, I will focus on how they connect and organise what they say. In fact, the language of second language (L2) users, especially of learners who have mainly studied the language in a classroom setting, seems to be quite static, a series of 'frozen chunks'. This might be a consequence of the input they received in the classroom environment, where they were taught 'functions', the language that they can use to perform particular actions, always applicable to any situation and context, like a maths equation, where $1+1$ is always 2 . 
Because of the input they receive from the world outside them, they might tend to structure their speech in a different way and use words, particles or connectors that they did not use before. These markers, often referred to as 'discourse markers' in linguistics, are so frequent in our first language that we cannot even utter a sentence, without saying 'you know', 'I mean' or 'well'. However, they are not that frequent in the speech of L2 users, as they have probably never been taught how to self-correct their thoughts, or how to convey a particular feeling while speaking. These words do not add a particular meaning to what is said ('John won the lottery' = 'John won the lottery, would you believe it!') but, at the same time, they are not simply added to it. They make the conversation sound more real, more native-like; in other words they have an important pragmatic function.

Therefore, my research is investigating whether students start using discourse markers differently in their speech after living abroad for a while. The research is mainly interview based and includes two interviews, one upon arrival in Ireland and the second one a few days before students' departure. This longitudinal approach will help to assess whether there is a change in the way students tend to organise their speech after the experience abroad by comparing the results of the two interviews. In order to favour the production of natural and spontaneous conversation, a friendly setting has been reproduced and interviews have been conducted while having a coffee with the participants. Topics of the interviews ranged from daily routine, university studies, future plans and differences between Ireland and their home countries. The transcription of the interviews has allowed to analyse the most frequent markers used by each speaker and to compare the results with those of the other participants, in order to assess trends, similarities and differences.

In addition to the participation in the interview, participants have been also asked to complete two questionnaires, one upon arrival and the other one before their departure. These questionnaires have been devised to provide information about the informants' learning expectations, their degree of interaction with the local community and to corroborate information given during the oral interviews. Preliminary findings suggest that the experience abroad seems to favour the use of more markers in learners' speech. Some learners also started using some discourse markers typical of Irish English, such as the use of 'like'. It is hoped that further research and the collection and analysis of more data will corroborate those preliminary findings and will help to assess whether a link exists between a study abroad experience and the development of some native-like features in speech.

\section{Towards a new concept of proficiency}

What is 'native-like' then? A lot of people think that 'native-like' might be connected to an extensive knowledge of lexicon or grammatical accuracy. That is true, but it is not limited to that! Knowledge of variation is also a fundamental part of speakers' abilities, and to become proficient in a foreign language, learners might need to acquire some native speakers' patterns of variation. This might lead to rethink the concept of proficiency 
according to new socio-pragmatic terms, where the prefix 'socio', added to the word 'pragmatic', stresses the importance of the social dimension of the language. In a study abroad context learners may improve their lexicon, fluency, grammatical accuracy, but there is more beyond words and grammatical rules that they can learn and this has to be considered when assessing the language development of students in a study abroad context.

I would like to thank my supervisors, Dr Martin Howard (University College Cork) and Dr Paolo Donadio (University of Naples Federico II), for their invaluable support, insight, and encouragement while conducting this research. I am also extremely grateful to the volunteers, who kindly agreed to take part in this project, and the UCC Strategic Research Fund for making this research possible. I also would like to express my gratitude to the Department of Humanities and the Department of Political Science of the University of Naples Federico II. 